\title{
Acercamiento a cuatro creaciones relativas a Manuel Rodríguez desde la crítica periodística de la época del cine mudo y de la era pre cinematográfica
}

\author{
Approach to four creations dealing with Manuel \\ Rodríguez from the point of view of silent movies times \\ journalism critique and pre cinema era journalism critique
}

\section{Eliana Jara Donoso ${ }^{1}$}

\section{Carmen Luz Maturana Araneda ${ }^{2}$}

Facultad de Letras UC.

cmaturaa@uc.cl

\begin{abstract}
Resumen
Se plantea un acercamiento a tres películas mudas $(1925,1920,1910)$ y a un espectáculo visual pre-cinematográfico (1824) referidos a Manuel Rodríguez. Se busca comprender, por medio de un análisis lingüístico acotado, la referencia que se hace de ellas en textos periodísticos de la época. Los registros periodísticos permiten un acercamiento a la gestación de la crítica cinematográfica en Chile, desde un eje temático que se interesa en su emergencia y evolución. Las principales conclusiones muestran una progresiva delimitación de las áreas de trabajo involucradas en la creación, así como de una paulatina diferenciación entre la actuación teatral y la cinematográfica. Se aminora cualquier consideración negativa y se asignan acciones humanas al material, como una forma de poder definirlo.
\end{abstract}

Palabras clave: Manuel Rodríguez, cine mudo, proyección visual precinematográfica, crítica cinematográfica.

1 Eliana Jara Donoso: periodista de la U.C. Trabajó en temas culturales en las revistas Solidaridad y Apsi y realizó investigación de la industria cultural en Ceneca, Flacso e llet. Su labor se centró en la investigación del cine mudo chileno, en la historiografía del cine Panamericano y en la recuperación de la memoria audiovisual. Falleció el 1 de diciembre de 2012.

2 Carmen Luz Maturana: es diseñadora teatral y magister en lingüística de la U.C. Ha centrado su labor investigativa en el teatro de sombras y en espectáculos teatrales de la era pre cinematográfica. 


\begin{abstract}
An approach to three silent movies is dealt together $(1925 ; 1920 ; 1910)$ with a visual show of the pre-cinema era (1824), all of this is referred to Manuel Rodriguez. The analysis is centered in understanding through a delimited linguistic study of how they are referred to in printed texts of those days. Journalism records allow a rapprochement to the birth of cinema critique in Chile from a theme axis interested in its emergence and evolution. The main conclusions show a progressive delimitation on the part of the critique of the working areas involved in the creation, as much as a gradual differentiation between the theatrical and the cinematic acting. Furthermore, any negative consideration is diminished apart and is giving human actions to the visual material as a way of being able to define it in a more concrete manner.
\end{abstract}

Keywords: Manuel Rodríguez, silent film, light-projected pre-cinematographic effects, film critic.

\title{
Manuel Rodríguez: un acercamiento a la gestación de la crítica cinematográfica en chile
}

De los ochenta y un argumentales y dos dibujos animados registrados entre 1916 y 1934, sólo el Húsar de la Muerte está en condiciones de ser exhibido en la actualidad. Perdida esta fuente inicial, y bajo la premisa de que no quedan restos visibles de la producción de esos años, la búsqueda de antecedentes en los diarios y revistas de la época permite atisbar los elementos y criterios empleados para juzgar el cine nacional y la respuesta del público a tales expresiones. Las intenciones con que se aborda esta etapa son el producto de la necesidad de contar con elementos objetivos que contribuyan a su evaluación y que sirvan de base para futuras investigaciones, porque este período está lejos de ser agotado en cuanto a nuevas indagaciones e incluso, rectificaciones.

Este artículo, en particular, busca un acercamiento a material fílmico y precinematográfico referido al personaje de Manuel Rodríguez, por medio de la indagación en los comentarios críticos del periodismo de la época. Se considera para ello textos referidos a tres películas mudas $(1925,1920$ y 1910) y un espectáculo previo al cine (1824): un trabajo escénico de proyección visual del siglo XIX que presenta visualmente un cuadro alusivo a Manuel Rodríguez en una función con linterna(s) mágica(s). Nos interesa resaltar el hecho de que las creaciones se vinculen al personaje histórico ya que su rol como guerrillero lo ha convertido en un personaje arquetípico, legendario, cuyas acciones lo señalan como un ícono fundamental de la resistencia independentista. Su asesinato en las cercanías de Tiltil, en 1818, mientras era trasladado a la cárcel de Quillota y en momentos en que O’Higgins era Director 
Supremo, potenció aún más el hecho de que trascendiera en la memoria colectiva nacional casi como un héroe legendario. Los registros periodísticos permiten dar cuenta de la permanencia del personaje en el imaginario social y posibilitan, además, un acercamiento a la gestación de la crítica cinematográfica en Chile, desde un eje temático que se interesa en su emergencia y evolución.

\section{Configuracion de la realidad en los textos}

La perspectiva de análisis se sustenta en la consideración de que el lenguaje permite que las personas se formen una imagen de la realidad que tienen a su alrededor y en su interior. En este proceso, individual y social a la vez, la construcción de la realidad es inseparable de la construcción del sistema semántico que la codifica (Halliday, 1982, p. 9). Por lo anterior, se indaga en la imagen de la realidad que los usuarios de la lengua configuran en sus textos. El presente análisis se focaliza en las estructuras transitivas, que expresan significados representacionales. Así, la oración gramatical, como expresión lingüística, se concibe como un proceso de relación mental en el cual los participantes descritos asumen determinados roles y donde el lenguaje es utilizado para hablar de las experiencias acerca del mundo, incluyendo los mundos creados mentalmente, para describir los eventos, hechos y entidades que están involucrados. La oración modela una entrada para representar la experiencia: el principio de que la realidad está compuesta de procesos. Desde esta perspectiva, la realidad se codifica en el lenguaje a través de diferentes procesos, que permiten interpretar las experiencias de una manera dinámica.

No hay duda de que la película muda más conocida sobre Manuel Rodríguez es El Húsar de la Muerte (1925). Sin embargo, existen dos cintas desaparecidas que precedieron esta creación. Una de ellas es la película de 1920 Manuel Rodríguez, dirigida por Arturo Mario, con guión de Rafael Raveau. Otra película que reelaboró al personaje es Manuel Rodríguez, de 1910, de Adolfo Urzúa. Como ya se mencionó, se agrega a estas películas mudas un espectáculo de proyecciones ópticas, dirigido por Félix Tiola, que incluía un cuadro visual referido al personaje y que se presentó en Santiago en 1824. A través del análisis discursivo de seis textos periodísticos, se plantea un acercamiento a elementos y juicios de análisis de la crítica de cada uno de los períodos. Se mantiene en todas las citas la ortografía original. ${ }^{3}$

3 Sólo en 1927 se decreta por ley como oficial en Chile la ortografía académica. 


\section{El Húsar de la Muerte (1925): hacia una terminología específica}

Desde su estreno, el 24 de noviembre de 1925, se convirtió en un éxito de público tal, que hoy sobrevive gracias a tres restauraciones. La primera de ellas fue hecha en la década del treinta, por autores desconocidos; la segunda, terminada en 1963 por el cineasta Sergio Bravo, fundador del Centro de Cine Experimental de la Universidad de Chile, quien en 1964 le incorporó música incidental compuesta especialmente por Sergio Ortega ${ }^{4}$; y la última, realizada por el restaurador Daniel Sandoval para la División de Cultura del Ministerio de Educación en 1995, con una nueva banda de sonido compuesta por Horacio Salinas. En 1998 el largometraje fue declarado Monumento Histórico. La película, dirigida, escrita y protagonizada por Pedro Sienna, tuvo un éxito indiscutido. Las opiniones de los diarios están sintetizadas en los comentarios de dos críticos bastante severos: Catón, de La Estrella de Valparaíso (19 de diciembre de 1925), y EX, de la revista Zig Zag (19 de diciembre de 1925).

La crítica de EX se inserta en dos páginas donde no hay una intención de relacionar la fotografía ni el texto dentro de la diagramación. Por el contrario, las referencias fotográficas son para "Adelqui Migliar, artista chileno, nacido en Talcahuano, que triunfa en Londres". Lo anterior da cuenta de que, salvo la relación temática general (el cine), no hay necesidad de manifestar una relación multimodal entre el lenguaje verbal y el visual (ver figura 1).
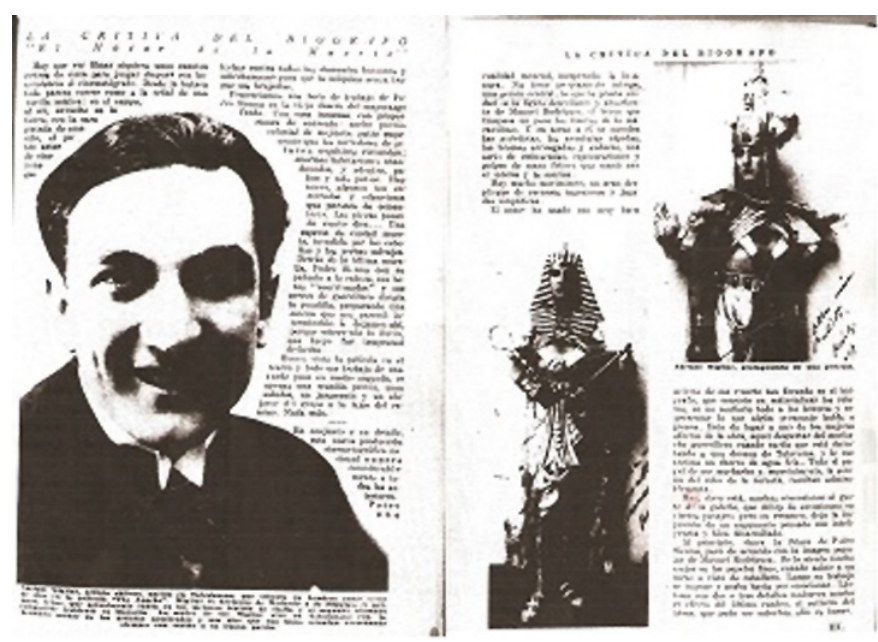

Imagen 1. La diagramación (Zig Zag, 19 de diciembre de 1925: 86-87) presenta una ausencia de relación multimodal entre el lenguaje verbal y el visual.

4 Con financiamiento Fondo de la Música del Consejo Nacional de la Cultura y las Artes, la Cineteca de la Universidad de Chile rescata durante el período 2008-2009 la única copia existente del registro realizado en 1964 de la composición creada por el música Sergio Ortega (Cineteca U de Chile, 2013). 
Enel textopropiamente tal, se utilizanverbos que dan cuenta de procesos materiales para definir la experiencia fílmica. Es decir, se reconstruye lingüísticamente la acción creativa utilizando verbos que requieren energía y que se refieren al mundo exterior. En particular, se naturaliza la acción creativa y así el crítico conecta a interpretaciones específicas la creación fílmica ("supera", "posee", "traspasa", etc.).

En conjunto y en detalle, esta nueva producción cinematográfica nacional supera considerablemente a todas las anteriores. Posee una cualidad esencial, inesperada: la livianura. No tiene propiamente intriga, una acción central: lo que le presta unidad es la figura descollante de Manuel Rodríguez, el héroe que traspasa un poco los límites de lo maravilloso. Y en torno a él se suceden las anécdotas, las aventuras rápidas, las bromas arriesgadas y audaces, una serie de emboscadas, equivocaciones y golpes de mano felices que mantienen el interés y la sonrisa (Zig Zag, 19 de diciembre de 1925, p. 86).

Dentro de los tres períodos observados relativos al cine mudo (1925, 1920, 1910), es la primera vez que hay una diferenciación explícita del actor de cine del actor teatral, así como una reflexión respecto del paso de la actuación en vivo al registro audiovisual:

... el pobre actor de cine tiene que luchar contra todos los elementos humanos y sobrehumanos para que la máquina negra trague sus brujerías. Presenciamos una hora de trabajo de Pedro Sienna en la vieja chacra del mayorazgo Cerda. Una casa inmensa, con proporciones de convento, ancho portón colonial de mojinete, patio empedrado que los corredores de pilares raquíticos circundan... Una especie de ciudad muerta, invadida por las cebollas y las yerbas salvajes. Detrás de la última muralla Pedro Sienna con su pañuelo a la cabeza, sus botas "acorrionadas" y sus arreos de guerrillero dirigía la pandilla, preparando una escena que nos pareció interminable. Hemos visto la película en el cine y todo ese trabajo de una tarde pasa en medio segundo, es apenas una reunión previa, unos saludos, un juramento y un alejarse del grupo a lo lejos del camino. Nada más. En conjunto y en detalle, esta nueva producción cinematográfica nacional supera considerablemente a todas las anteriores (Zig Zag, 19 de diciembre de 1925, p. 86).

Aún cuando la crítica de EX resalta los logros de la película de manera efusiva, cae al final del texto en el lugar común de fantasear con lo que pudría haber sido y no lo que es. "Lástima que dos o tres detalles malogren mucho el efecto del último cuadro, el entierro del héroe, que pudo ser soberbio, sólo es bueno" (Zig Zag, 19 de diciembre de 1925, pp. 86-87). Catón, por su parte (La Estrella de Valparaíso, 19 de diciembre 
de 1925 , p. 5), se concentra en el argumento, la acción, la trama y la fotografía para dar cuenta de la película y, en ese sentido, presenta menos reflexión y terminología específica sobre el proceso cinematográfico que EX.

Es esta cinta, comolo dijimos anteriormente, una cinta basada enlas hazañas más o menos auténticas de Manuel Rodríguez, la acción de la trama se desenvuelve fácil, ya que en buenas cuentas, no tiene un argumento perfectamente definido. Es más bien la realización de esas hazañas más o menos novelescas, y dentro de la cual se teje un corto y sencillo idilio y se deja entrever otro. La fotografía de esta cinta es buena, sin llegar a ser una cosa sobresaliente, teniendo, es de justicia reconocerlo, paisajes y cuadros verdaderamente preciosos (La Estrella de Valparaíso, 19 de diciembre de 1925, p. 5).

El crítico escribe favorablemente sobre los "papeles" de Pedro Sienna como Manuel Rodríguez y de Piet van Ravenstein como San Bruno. Sin embargo, quien capta su atención es el niño: "cuyo nombre no sabemos, que hace el papel de Huacho Pelao, que es verdaderamente admirable. Hay en él pasta de grande actor." La ausencia de ese dato, por ejemplo, le quita profundidad a la crítica de Catón. Dos días después aparece una entrevista en el mismo diario titulada "Conversando con el Huacho Pelao", lo que ayuda a corregir el olvido. Cuando se le pregunta el nombre, el actor de doce años responde: “¡Chiis! ¿No lo vio en la película cuando me presentan? Guillermo Barrientos es mi nombre” (La Estrella de Valparaíso, 21 de diciembre de 1925, p. 5).

\section{Manuel Rodríguez (1920): el primer intento de acercarse a una película histórica}

El 18 de mayo de 1920 se estrenó en el Teatro La Alhambra de Valparaíso la película Manuel Rodríguez, adaptación de Rafael Raveau de la novela Durante la Reconquista, de Alberto Blest Gana. Posteriormente, el 1 de junio, se estrenó en el Teatro Alameda de Santiago. La sociedad productora era Mario-Padín films y estaba conformada por los actores argentinos Arturo Mario y María Padín. Sus vínculos con el teatro, sin embargo, eran más profundos que con el cine y ejercían también como los líderes de la Gran Compañía de Dramas, Comedias y Vaudevilles Mario-Padín (Piña, 2009, p. 209). Además, participaron en el film Nicanor de la Sotta, Pedro Sienna como protagonista, Juan Pérez Berrocal, Clara del castillo, entre otros conocidos actores teatrales del período. 5

5 Se registra también la participación de Isaura Gutiérrez, Isidora Reyé, Aurora Salas, Héctor Dragoni, Enrique Conouet, Francisco Ferrer, Juan Tapia, Nicasio González, Juan Argomedo y 200 extras para las escenas bélicas (Jara, 1994, p. 49). 
Es el primer intento de acercarse a una superproducción histórica al estilo de las realizadas con gran éxito en Estados Unidos y Europa, especialmente en Italia. Si se revisa una historia mundial de cine, se verá cómo cada país al tratar de crear un cine nacional recurre a sus grandes figuras históricas y a sus epopeyas más heroicas y populares en busca de elementos configurativos de la nacionalidad e idiosincrasia del país. Chile no ha sido una excepción, aunque dentro del total del período del cine mudo, los asuntos históricos constituyen una temática secundaria.

Los diarios publicitan en forma profusa el film, primero en Valparaíso y días más tarde para su estreno en Santiago, comentan y elogian distintos aspectos de la cinta: los paisajes, la nitidez de la fotografía y sus efectos de luz; los encuadres, la naturalidad de la actuación de Pedro Sienna; la colaboración del Museo de Historia Natural que proporcionó los uniformes, muletas y armamentos, o de cómo se reconstruyó la fachada de la Catedral de Santiago para la escena del fusilamiento del coronel del ejército español San Bruno, del Regimiento Talavera, con un costo de veinte mil pesos. En El Chileno (1920) aparece un comentario que entrega algunas luces sobre la benevolencia de la crítica y el poco rigor técnico de los productores y su carácter promocional.

En vespertina y nocturna en el Alhambra y en nocturna a las 9 en punto en el Palace, se exhibirá hoy por últimas veces y a petición de numerosas familias la gran película histórica nacional Manuel Rodríguez que ha obtenido éxitos lisonjeros. Sabemos que en el film se han efectuado algunas innovaciones apreciables y agregado algunas escenas que por la premura del día del estreno no pudieron intercalarse (El Chileno, 20 de mayo de 1920, p. 5).

El crítico del diario La Unión de Valparaíso, bajo las iniciales O.V. describe la película en una extensa columna titulada Una Cinta Nacional-Manuel Rodríguez (20 de mayo 1920). Al analizar el texto con la intención de ver la manera en que codifica verbalmente la experiencia, se observa la materialización del film como un actor que realiza acciones mentales. Es así como el crítico utiliza verbos que dan cuenta de procesos cognitivos ("augura”, "interesa”, "llama la atención”), vinculados a la experiencia y al mundo interior, asociados a los sentidos, a los pensamientos y a la percepción, para así expresar sus propias expectativas respecto del film, pero asignadas a la película como si ésta fuera una entidad personalizada, dotada de conciencia.

Manuel Rodríguez como película pie, además del esfuerzo positivo que revela, abre márgen eficiente al desenvolvimiento de la hermosa idea propuesta y augura una fecunda cosecha artística y financiera. Ojalá que este empeño por nada se desanime y que sus propagandistas prosigan, con el tesón hecho ostensible en la primera producción, trabajando por el futuro de esta industria- 
arte que rinde resultados positivos tales que en corto tiempo, pueden traducirse en prosperidad muy manifiesta. "Manuel Rodríguez" aparte de su fotografía que es dura y escasa de experiencias en determinadas escenas, interesa por su asunto y llama la atención por la sobriedad con que trabajan sus elementos participantes (La Unión, 20 de mayo de 1920, p. 7).

Se utilizan también verbos relacionales atributivos para describir la película e interpretar la experiencia de una manera dinámica, por medio del verbo "ser", el que establece una relación entre dos partes o entidades diferentes. El que sea atributivo indica que una de esas partes es un atributo de la otra, es decir, se atribuye una cualidad a la entidad analizada. Por lo anterior, además de establecer una relación entre dos entidades separadas, generan la posibilidad de clasificar.

Antes de escribir sobre esta cinta, debemos declarar que, teniendo presente los elementos con que se realizó, "Manuel Rodríguez" es una obra que honra las iniciativas y el esfuerzo cinematográficos nacionales. Y aún más, si tenemos en consideración que esta película es la base sobre la cual se quiere implantar la futura industria del cine en Chile, al primer aplauso tributado deberíamos agregar el elogio entusiasta. Hasta hoy sólo hemos tenido por acá esfuerzos aislados, iniciativas que levantándose con muy sinceros propósitos, se estagnaron $[\mathrm{sic}]$ repentinamente por razones que estaría de más consignar ( La Unión, 20 de mayo de 1920, p. 7).

Además de las valoraciones favorables para describir el material (esfuerzo positivo, hermosa idea, empeño), el texto resalta el tesón que implicó la concreción cinematográfica:

Ojalá que este empeño por nada se desanime y que sus propagandistas prosigan, con el tesón hecho ostensible en la primera producción, trabajando por el futuro de esta industria-arte que rinde resultados positivos tales que en corto tiempo, pueden traducirse en prosperidad muy manifiesta $[\ldots]$. No terminaremos estas líneas sin aplaudir el esfuerzo enorme que representa "Manuel Rodríguez" y alentar con la sinceridad que nos caracteriza la iniciativa laudable y al fin realizada con vastas perspectivas por los señores Rafael Raveau y Arturo Mario (La Unión, 20 de mayo de 1920, p. 7).

Los atributos mencionados sirven para sustentar la carga positiva que se le asigna en el texto a la película, que le otorga un carácter fundacional respecto del cine que se habría de desarrollar posteriormente. Sin embargo, también es posible detectar algunas representaciones negativas de la experiencia, que personifican el elemento al cual se hace referencia como si fuera una entidad material: 
Es cierto que la presentación del héroe peca por débil empleo del resorte efectista, tratándose de la figura principal, y que sus hechos legendarios aparecen episódicos y no eslabonados con firmeza a la intriga dramática de los trágicos amores de Luisa Bustos y Abel Malsira, y que en este desenlace desaparece, hasta en la posible evocación, el nombre de Rodríguez, pero estos pequeños lunares, fáciles de subsanar, palidecen ante la magnitud del esfuerzo reconstructivo que se ha hecho de la época y del noble espíritu que la alentó, al desenvolverla en un asunto movido y de interés (La Unión, 20 de mayo de 1920, p. 7).

Como se percibe en el párrafo anterior y en el siguiente, el crítico matiza siempre las opiniones negativas por el uso de conjunciones y nexos adversativos ("pero", "sin embargo"), con la intención de contraponer a los conceptos de desaprobación emitidos algún tipo de justificación que los aminore:

Hay titubeos que hablan de escaso conocimiento en el personaje interpretado, pero son defectos comunes que no desaparecerán del teatro y del cine hasta que los elementos artísticos tengan la conciencia suficiente de que es imposible hacer una escena sin conocer el argumento de la obra y la línea total del personaje cuya interpretación se les encomienda. Conocemos a muchos que se jactan de experiencia en materia teatral y que jamás ponen en práctica el elemental aforismo de que "a papel sabido no hay cómico malo". Sin embargo, en la interpretación de esta película ha habido mayor sobriedad que en las anteriores de factura nacional (La Unión, 20 de mayo de 1920, p. 7).

La constante discursiva es adjudicar acciones al film como su fuera una entidad material y humanizada, para demostrar que la crítica negativa da cuenta de una situación habitual en la actuación de la época, no atribuible directamente a la película, lo que permite la atenuación. Por otra parte, el texto anterior muestra que las diferencias de la actuación teatral y la cinematográfica son poco definidas para el crítico. Asimismo, el cine es definido como "industria-arte" y como "fotografía animada”. La terminología utilizada para referirse las áreas de trabajo y funciones laborales son "los propagandistas", "el autor", "la dirección artística", "el operador del film" y "el trabajo de reconstrucción". La "labor artística” se utiliza como sinónimos de actuación.

Ojalá que este empeño por nada se desanime y que sus propagandistas prosigan, con el tesón hecho ostensible en la primera producción, trabajando porelfuturo de estaindustria-arte que rinderesultados positivos tales queen corto tiempo, pueden traducirse en prosperidad muy manifiesta ( ... ). Además 
hay que tener presente que el autor en la obra de carácter histórico tiene que ceñirse estrictamente a las fuentes informativas sin poder hacer despliegue de fantasías ni de originalidades, como en [una] pieza de la época actual ( ... . . El trabajo de reconstrucción no deja qué desear y se arvierten [sic] posesión y conocimientos. La dirección artística coadyuvó eficientemente al buen éxito de "Manuel Rodríguez", revelándose experimentada aunque no múltiple en el acierto de sus combinaciones escénicas. La labor artística del señor Sienna, de la señora Padin, del señor de la Sotta, del señor Bettancourt y muy en especial de los señores Mario y Ferrer, es destacada y natural ... Operador de este film fue el señor Nicolás Aguilar, joven sureño, que por primera vez afrontaba un trabajo de tamaña responsabilidad, revelándose con él como una promesa en el difícil arte de la fotografía animada.

El párrafo final resume bien la actitud positiva ya mencionada previamente y que prevalece en el texto, el que aún cuando considera aspectos negativos, los aminora al dar cuenta de la dificultad que entrañaba hacer cine. "No terminaremos estas líneas sin aplaudir el esfuerzo enorme que representa Manuel Rodríguez y alentar con la sinceridad que nos caracteriza la iniciativa laudable y al fin realizada con vastas perspectivas por los señores Rafael Raveau y Arturo Mario (La Unión, 20 de mayo de 1920, p. 7)".

\section{Manuel Rodríguez (1910): la primera película argumental chilena}

En 1910, la cinematografía nacional registra un estreno de importancia. El 10 de septiembre se exhibió la primera película argumental de la que se tenga conocimiento en Chile, Manuel Rodríguez, producida por la Compañía Cinematográfica del Pacifico $^{6}$. Con la intención de preparar a un grupo de actores y de realizar una serie de películas argumentales para la celebración del centenario del país, la empresa contrató al director teatral, dramaturgo y profesor Adolfo Urzúa Rosas. No hay información sobre el equipo técnico y tampoco se sabe el nombre de los intérpretes, salvo un indicio publicado en 1926 en una crónica escrita por el dramaturgo Antonio Acevedo Hernández (Jara, 1994, p. 25). Menciona que en la película participaron Nicanor de la Sotta, Francisco A. Ramírez, Filomena Flores y Carlos Prats. Algunos de ellos volverían a participar en otras producciones, especialmente de la Sotta, quien además participó en la película Manuel Rodríguez, de 1920.

6 El algunos medios la nombran también como "Pacífico Films". 
La reacción de la prensa fue favorable, si se toma en consideración los dos textos periodísticos detectados. El primero es una nota aparecida en el diario El Ferrocarril, el 10 de septiembre de 1910, en la sección Teatros. Ahí se da cuenta de algunas impresiones emitidas por un autor no especificado: "fue invitado un miembro de la redacción de este diario, como también de los demás órganos de publicidad, a presenciar el estreno de una película de Manuel Rodríguez en el Biógrafo Kinora, que funciona en el Teatro de Variedades" (10 de septiembre de 1910, p. 4). El Mercurio, por su parte, incluye una crítica firmada por Rosina Storchio, en la sección de Espectáculos (10 de septiembre de 1910, p. 7).

El Ferrocarril presenta discursivamente a la película como miembro de dos categorías: la primera, la de las vistas más hermosas que se puede ofrecer al público y la segunda, por medio del atributo patriótica: "Es sin duda, una de las vistas mas hermosas que se puede ofrecer al público, por ser, en primer lugar, patriótica, pues recuerda los hechos más emocionantes de la vida ajitada del guerrillero, Manuel Rodríguez; y en segundo lugar, por sus paisajes" (El Ferrocarril, 10 de septiembre de 1910, p. 4). No se especifica una causa o agente externo para estructurar el proceso al que se hace relación (se puede ofrecer al público) y discursivamente no se presenta a quienes fueron los encargados de ofrecer la vista al público, pero sí se menciona una entidad vinculada a los gastos: la empresa.

La naturaleza privilejiada de este país ha sido reproducida en la forma más feliz en la mencionada vista. La empresa espera que el público sabrá corresponder a los gastos que ha demandado la película de Manuel Rodriguez. Con esta estensa película se estrena la ejecución de esta clase de trabajos en el país. La empresa espera que el público sabrá corresponder a los gastos que ha demandado la película de Manuel Rodriguez (El Ferrocarril, 10 de septiembre de 1910, p. 4).

Al igual que en los ejemplos referidos a la película de 1920, el periodista personaliza a la empresa por medio de un verbo de comportamiento ("esperar") y se generaliza a todos los actores sociales involucrados en la realización al presentarlos como pertenecientes a una entidad. Así, se los asimila como grupo o colectivo, borrando la individualidad de las labores realizadas. Además, al igual que la crítica de 1920, el texto le otorga un carácter fundacional a la película de 1910 ("se estrena la ejecución de esta clase de trabajos en el país”). La crítica de Rosina Storchio (El Mercurio, 10 de septiembre de 1910, p. 7), por su parte, personaliza en "la Empresa del Kinora" la invitación hecha a los periodistas para la exhibición de la película. Sin embargo, identifica al responsable de la acción creativa: el profesor Adolfo Urzúa. 
Ayer en la tarde la Empresa del Kinora invitó a un grupo de periodistas para hacer la primera proyección de las películas para el Centenario ha estado preparando el profesor Urzúa Rosas, sobre temas de historia nacional. Las películas están tomadas de representaciones hechas por el cuadro que dirige el señor Urzúa y el tema explotado son las aventuras del guerrillero de la independencia, Manuel Rodríguez. Como primer ensayo de esta forma de popularizar la historia patria, el éxito es bueno.

No hay una definición de labores ni del elenco salvo Urzúa, quien aparece como responsable por medio de la acción concreta de "dirigir". La crítica también relaciona un atributo al film ("bueno") y le impregna una valoración positiva al representarlo por medio de una cualidad: "el éxito". Las consideraciones negativas también se mencionan.

Los paisajes han sido bien elegidos y las escenas están reproducidas con corrección. Sin embargo, apuntamos algunos detalles de que conviene toma nota el director de la compañía que hace la representación de los cuadros á fin de que los subsane en posteriores ensayos. Las mujeres que salen a besar la imagen que lleva el ciego deberían tener una indumentaria menos cuidada. Hay soldados que hacen varios disparos sin cargar sus rifles, que debemos suponer son de chispas. De todos modos la empresa acometida por la compañía cinematográfica del Pacífico es digna de todo encomio.

La manera en que se expresa el cuestionamiento, sin justificaciones y sin delimitar las áreas de trabajo profesional a subsanar, presentándolas como "detalles", dan cuenta de los pocos elementos de análisis relacionados al cine que se explicitan en la crítica. Después de la consideración negativa, y como una constante en los textos revisados, se aminora el comentario y se resaltar el trabajo ("De todos modos la empresa acometida por la compañía cinematográfica del Pacífico es digna de todo encomio").

\section{Manuel Rodríguez: un espectáculo "inmoral", 1824}

Se detectó un espectáculo pre cinematográfico en la prensa nacional del siglo XIX, referente a Manuel Rodríguez. Se trataba de una realización visual con efectos de proyección por medio del uso de linternas mágicas y/o otros aparatos ópticos, usados para escenificar cuadros. Principalmente, se mostraban transformaciones y proyecciones de fantasmagorías, es decir, la representación ante el público de espectros por medio de la ilusión óptica. Félix Tiola, responsable y autor de la creación, cuyo título no aparece mencionado, era un italiano avecindado en Chile que se había presentado al público en 1821, por medio de un aviso en la prensa local: 
Félix Tiola, profesor de física divertida, tiene el honor de anunciar a este respetable público, que habiendo trabajado en Europa en las mejores fábricas de París, y de Ginebra en el arte mecánico de relojería, ofrece a este público sus servicios de componer toda clase de relojes, sean de escape como de música, y cajas de música, y todo lo que pertenece al arte mecánico, trabaja en la calle de la Merced cerca de la plaza, en la tienda de D. Juan Avello. NOTA: Si en esta capital hubiese algunos aficionados que quisiesen aprender las pruebas que contiene el gabinete de física de éste, se ofrece a enseñarlos y construir las máquinas necesarias para ella, a un precio cómodo para todo aficionado (Feliú, 1964, pp. 327-328).

El 4 y 5 de abril de 1824, la prensa da cuenta de un espectáculo de proyección realizado por Tiola como parte del aniversario número seis de la batalla de Maipú. Presentó una serie de cuadros que incluían la proyección, por medio de la óptica, de sucesos dedicados al pueblo chileno. El día 10 de abril apareció en el diario El Avisador Chileno (1824, pp. 22-23) una columna que hacía referencia a uno de los cuadros, relacionado con Manuel Rodríguez. Como se puede apreciar en la reproducción, la descripción del cuadro visual no aporta elementos críticos a la materialidad de la presentación, más bien la describe someramente. El interés del texto no es el espectáculo como tal, pero sí se asume una posición explícita, emotiva y valorativa, respecto del personaje histórico y la batalla de Maipú, donde Manuel Rodríguez estuvo al mando del regimiento de caballería Los Húsares de la Muerte. Se percibe una alusión explícita a su asesinato, cuya sexta conmemoración, el 26 de mayo, se cumpliría algún tiempo después de la presentación.

... se dejó ver a la Diosa Cagliopo sentada sobre un sepulcro adornado de jazmines y mirtos y elevado sobre un túmulo de enlutados atambores, escribiendo en su gran rejistro lo siguiente: HOY MANUEL RODRIGUEZ SALVO A LA PATRIA. Los vivas, y aclamaciones de los espectadores a las cenizas de este héroe, fueron ilimitadas. Se pidió su repetición para contemplar con lagrimas en los ojos una memoria tan grande y execrar á sus verdugos, renovándose en sus corazones el augusto momento que supo erijirle la gratitud por los servicios que prestó en aquellos días a la Nacion precipitada al borde de un eminente peligro. Dias memorables en que los laureles conseguidos en el campo de honor, se matizaron con la sangre de Rodríguez vertida alevosamente sobre la tierra que acababa de libertar, y cuyos grandes echos de heroísmo no pudieron mirar sus asesinos sin la emulación propia de almas que no reconocieron jamás el camino de la virtud, por donde condujo a sus conciudadanos a vencer a los fieros opresores de su patria. Ciudadanos: recordad siempre aquellos días de desgracia y confusión, en que no mirabais 
alrededor mas que peligros y desolación sin esperanza de remedio. Veteranos defensores del estado que con pasos inciertos marchavais á traspasar los Andes, por que no hallavais quien os condugece á vencer. Jovenes del rejimiento de la muerte que os reunisteis en 12 horas á la conducta de Rodríguez y marchasteis á buscar al agresor victorioso. Soldados de Aconcahua que corriste á poneros bajo sus ordenes. Sexo amable que llorabais la perdida de vuestros maridos, hijos, parientes y hermanos: volved la vista á los campos de Quillota y veréis al que os reanimó, al que os condujo á vencer, al que os restituyó vuestras caras prendas coronadas de laureles, y a la patria libre, vertiendo su sangre derramada alevosamente y traspasado por la mano sacrílega de un español mercenario, el corazón mas valiente y mas generoso que se vio sobre la escena de nuestra revolución. ¡Sombras honorables! Que las virtudes que te han colocado sobre los Titos, Trajanos, Washington, Sinsinatus, sean el modelos que imitemos y el eterno dogal de vuestros asesinos.

La codificación discursiva no se interesa en la representación del público sino que en sus acciones ("los vivas y aclamaciones"). Algunos efectos de este procedimiento discursivo es que se pone en un segundo plano la identidad del actor social y se otorga fuerza a una acción de éste, agregando, en este caso, connotaciones positivas a la acción (van Leeuwen, 2008, p. 47). Lo mismo sucede al no especificar un agente que actúe directamente en la consecución del evento que denotan los procesos de comportamiento: "Se pidió su repetición para contemplar con lagrimas en los ojos una memoria tan grande y execrar á sus verdugos ..."

El 7 de abril de 1824, dos días después de la presentación, el senador Juan Egaña presentó una moción formal en el Congreso para referirse a la presentación, la que quedó registrada y aprobada en el acta del senado de la sesión. En el sumario introductorio aparece descrita como "espectáculo inmoral" y se generó una moción oficial de censura (Letelier, 1887, p. 242). Lamentablemente, el texto de El Avisador Chileno no da pistas claras del espectáculo como tal, salvo una breve frase que da cuenta del momento a oscuras que se presenciaba en el escenario, alumbrado por la luz que emitía la proyección y a la cual se le adjudica una característica humana, para poder definirla: “... el corazón mas valiente y mas generosos que se vio sobre la escena de nuestra revolución, ¡Sombras honorables!”. Al contrario de los textos referidos a las películas mudas, no hay un interés en describir el espectáculo ni esbozos de un análisis crítico. Motivados por la cercanía temporal del asesinato de Manuel Rodríguez, son su figura y su significado simbólico el que genera las reacciones del texto. 


\section{Conclusiones}

Los textos muestran el desarrollo de una crítica incipiente, que da cuenta de una progresiva delimitación de las áreas de trabajo involucradas en las creaciones, y cuya conceptualización va incrementándose según avanza la fecha de publicación. Asimismo, se evidencia una escasa diferenciación entre la actuación teatral y la cinematográfica, a excepción de la crítica de EX a El Húsar de la Muerte (Zig Zag, 19 de diciembre de 1925). Un recurso discursivo utilizado para definir la experiencia es la personalización de la creación visual como un objeto material que realiza acciones humanas energéticas, lo que permite definir los procesos involucrados en la representación de la experiencia de una manera más clara para el lector y, posiblemente, para los mismos periodistas. Otra constante discursiva es asociar la creación, por medio del verbo "ser" a algún atributo de connotaciones positivas.

Se trata de una crítica que no desarrolla en profundidad sus elementos y juicios de análisis, aún cuando se percibe una progresiva delimitación de las áreas de trabajo y roles involucrados, según sea la fecha de escritura. El texto de 1824 sólo diferencia al responsable principal; los textos de 1910 distinguen al director y la empresa. El texto de 1920 se refiere al autor, la dirección artística, el operador del film, el trabajo de reconstrucción y la interpretación, entre otros, especificando además el nombre de los involucrados. La crítica de 1925 diferencia al actor de cine, la locación, la producción cinematográfica, la escena, los efectos, las acciones de la película, al autor y por primera vez se habla directamente del público ("la galería") y no de sus acciones.

Las críticas referidas a las películas mudas diferencian los films de 1910 y 1920 como un tipo específico de creación, pero tienden a fusionar algunos aspectos con el teatro. En particular, lo referente al elenco y la actuación. Esta última se entiende como una actividad laboral que surge y experimenta a partir del oficio teatral, confundiéndose en algunos momentos ambas áreas de trabajo. El nexo también puede percibirse en los espacios físicos de presentación. El teatro Variedades, por ejemplo, estaba asociado al biógrafo Kinora y es el lugar donde fue exhibida la película de 1910. Sólo la crítica de EX (Zig Zag, 19 de diciembre de 1925) a El Húsar de la Muerte diferencia al cine como un producto cultural específico.

Los textos referidos a las películas mudas consideran algunos aspectos negativos de las creaciones, pero son aminorados siempre con alguna justificación, lo que podría dar cuenta de la comprensión respecto de la dificultad que entrañaba hacer cine. Además, se centran en el material visual y no hacen alusiones valorativas respecto del personaje ni su muerte. El texto de 1824, por su parte, no presenta la intención de hacer un análisis sino que, más bien, asume una breve postura descriptiva del espectáculo la que, en todo caso, permite dar cuenta de la experiencia en relación a la presentación como tal. Sin embargo, se focaliza en emitir juicios de valor y exaltar la figura de Manuel Rodríguez por sobre cualquier otra consideración. Nos pareció 
importante darlo a conocer como un ejemplo de escenificación pre cinematográfica porque, por una parte, da indicios de los trucos ópticos que luego fueron asimilados por el cine y, por otra, se vincula al personaje y a la intención de "revivirlo" a través de la proyección audiovisual.

Setenta y dos años después de esta presentación, en Santiago, un frío 25 de agosto de 1896, el teatro Unión Central abría sus puertas a las ciento cincuenta personas que concurrieron a presentar este revolucionario cambio en el mundo del espectáculo visual. Aún cuando el teatro perdió su relación con los efectos ópticos y la imagen proyectada durante la primera mitad del siglo $\mathrm{XX}^{7}$, el personaje de Manuel Rodríguez logró traspasar los formatos y ha estado presente a lo largo de la historia filmográfica y pre-cinematográfica nacional. Su muerte, además de dar cuenta de un sórdido suceso, forma parte de la historia de Chile y ha incrementado la conformación de un personaje con caracteres de leyenda y un referente de compromiso político rebelde frente al poder oficial. Ha sido un tópico recurrente en diversas creaciones artísticas, no sólo en el cine, y forma parte también de la memoria colectiva del país. Sin embargo, y más allá de la preeminencia del personaje como arquetipo visual, el cine del período así como los espectáculos cinematográficos del siglo XIX estuvieron lejos de intentar plasmar en imágenes la etapa histórica que les tocó vivir.

7 La excepción la constituye la obra "Tristán Machuca". El director, Luis Rojas Gallardo, incorporó en la pieza teatral un episodio filmado (Jara, 1994, p. 117). 


\section{Referencias bibliográficas}

Catón. (1925, 19 de diciembre). "El Húsar de la Muerte". La Estrella de Valparaíso. pp. 5

Cineteca Universidad de Chile (2013). "Películas restauradas". Obtenido el 10 de enero de 2013 en http://www.uchile.cl/portal/extension-y-cultura/cineteca/ proyectos realizados/59001/peliculas-restauradas

EX. (1925, 19 de diciembre). "La Crítica del Biógrafo El Húsar de la Muerte." Zig Zag. pp. 86-87.

Feliú, G. (1964) Antiguos periódicos chilenos. Volumen IX. Santiago: Editorial Universidad Católica.

Halliday, M.A.K. (1982). El lenguaje como semiótica social. México: Fondo de Cultura Económica.

Jara, E. (1994). Cine mudo chileno. Santiago: Los Héroes.

Letelier, (1887). Sesiones de los cuerpos legislativos de la República de Chile -181 1 a 1845. Tomo IX. Santiago: Imprenta Cervantes.

O.V. (1920, 20 de mayo). "Una Cinta Nacional-Manuel Rodríguez". La Unión. pp. 7

Piña, J.A. (2009). Historia del teatro en Chile 1890-1940. Santiago: Ril.

s/a. (1824, 10 de abril). "Cinco de abril: teatro". El Avisador Chileno. pp. 22-23

s/a. (1910, 10 de septiembre). Biógrafo Kinora. El Ferrocarril. pp . 4

s/a. (1920, 20 de mayo). "Manuel Rodríguez."El Chileno. pp. 5

s/a. (1925, 21 de diciembre). "Conversando con el Huacho Pelao". La Estrella de Valparaíso.pp. 5

Storchio, R. (1910, 10 de septiembre). “Espectáculos".pp. 7

Van Leeuwen, T. (2008). Discourse and Practice. Oxford: Univerity Press. 